\title{
La influencia de la contabilidad creativa en la ética profesional del contador público
} The influence of creative accounting on the professional ethics of the public accountant

\author{
Cristian Hernández-Gil1 \\ Nelson Andrés Losada-Rodríguez2 \\ Daniela Orozco-Calderón3
}

Recibido: marzo 14 de 2019

Aceptado: junio 28 de 2019

\section{Resumen}

La contaduría pública, como carrera profesional liberal, nace de la necesidad de formar personas, de manera técnica, profesional y ética para que se especialicen y se encarguen del manejo de las finanzas de una persona natural o jurídica. Esto para una posterior presentación de informes financieros con cifras fidedignas, con el fin de perfeccionar el proceso de toma de decisiones, en la gestión de cualquier organización. El objetivo de esta investigación se centró en analizar la ética del profesional, su importancia y cómo la ausencia de la misma hace que se presente la contabilidad creativa. Se desarrolló una investigación de corte descriptivo y de tipo revisión documental, donde se analizaron 51 referencias bibliográficas. Se concluye que la contabilidad creativa es un flagelo que afecta la ética organizacional y profesional, de quien se presta a cometer actos fraudulentos, por la sencilla razón de acomodar cifras y mostrar una realidad que no corresponde con lo verdaderamente ejecutado.

Palabras clave: ética profesional, contabilidad creativa, contador público, práctica, manipulación.

\begin{abstract}
The public accounting as a professional career, born from the need to train people, in a technical, professional and ethical way to specialize and handle the management of the finances of a natural or legal person, for a subsequent presentation of financial reports with reliable figures, in order to perfect the development of the decision-making process from the management of any organization. Based on this, the objective of this research is to analyze the ethics of the professional, its importance and how the absence of it leads to the presentation of creative accounting. To this end, a descriptive and documentary review type research was carried out, in which 51 bibliographical references were analyzed. It is concluded that creative accounting is a scourge that affects the organizational and professional ethics of those who allow to commit fraudulent acts for the simple reason of accommodating figures and showing a reality that does not correspond to what is truly executed.
\end{abstract}

Keywords: professional ethics, creative accounting, public accountant, practice, manipulation.

1 Administrador de Empresas, Especialista en Mercadeo, Universidad de la Amazonia, Florencia, Colombia. E-mail: cris.hernandez@ udla.edu.co ORCID: 0000-0001-6512-2453

2 Estudiante de Contaduría Pública, Universidad de la Amazonia, Florencia, Colombia. E-mail: ne.losada@udla.edu.co ORCID: 00000002-4081-5373

3 Estudiante de Contaduría Pública, Universidad de la Amazonia, Florencia, Colombia. E-mail: dan.orozco@udla.edu.co ORCID:00000002-6101-5447 


\section{Introducción}

La correcta simetría que refleja la partida doble, es sinónimo de perfección: el juego del debe y el haber muestra la forma exacta de los registros contables de las operaciones financieras dentro de las empresas. Pero no siempre la teoría se aplica como debería ser, en ocasiones, los saldos no coinciden y no se encuentra motivo alguno en dicha disparidad; momento en el cuál, el contador público, debe demostrar sus destrezas profesionales para hallar una solución a la desigualdad en los saldos.

Actualmente, ha surgido una práctica que se encarga de acomodar las cifras contenidas en los saldos de los estados financieros, que tiene por objetivo revelar una imagen deseada de la situación financiera de la empresa y no la que debería ser, conocida como contabilidad creativa (Akbanuko \& Umoren, 2018). "Su propio nombre lleva implícito la condición de 'crear', cuando la contabilidad tiene como principal función el reflejo de la realidad" (Bravo-González, 2011).

En este sentido, de un lado se tiene la contabilidad creativa, práctica fraudulenta para unos, de habilidad y sagacidad para otros, pero al fin y al cabo como afirma Gay (1999) citado en (Guevara \& Cosenza, 2004), es:

(...) Una obra de arte de los grandes artistas y escultores de la contabilidad los contadores y los auditores quienes aprovechan las brechas de la normativa contable para armar un enredo fiscal o financiero, que les permita mostrar la imagen fiscal o empresarial deseada y sacar provecho de ello. (p. 9)

De otro lado se tiene la ética, la cual es inherente al ser humano y debe estar inmersa tanto en lo personal como en lo profesional. La ética promueve un comportamiento sano y libre, que lleva a actuar a cada profesional en función del bien o del mal; además, ayuda a reflexionar un poco sobre la elec- ción entre alternativas, las cuales se materializan en decisiones. Es por esto que los profesionales deben contar con ética $y$, en el caso de la contaduría pública, generar confianza ante la sociedad.

En este orden de ideas, actualmente el contador público desconoce la influencia que tiene la contabilidad creativa sobre la ética profesional; la misma, que se encuentra inmersa, proclamada y entregada en el momento en el que este recibe su título de pregrado y su posterior tarjeta profesional, los cuales le confieren confianza ante la sociedad. Es decir, la ética cumple con una función social a través de los profesionales (Gonzalo-Angulo \& Garvey, 2007).

El objetivo de este artículo consiste en reflexionar sobre la influencia de la contabilidad creativa en la ética del profesional en contaduría pública. Esto es relevante en épocas donde prima la corrupción en los procesos de contratación, consecución y administración de recursos de organismos públicos y privados. Lo anterior se asocia con los altos niveles de evasión de impuestos, tanto de personas naturales como jurídicas, que pone en riesgo el presupuesto, la riqueza, y la sostenibilidad del Estado.

\section{Metodología}

Se realizó una investigación de tipo recopilación bibliográfica y documental (Hernández-Gil, Figueroa-Ramírez \& Correa-Corrales, 2018). En ella se indagó, a través de 51 referencias bibliográficas, la influencia de la contabilidad creativa en la ética profesional del contador público. Se establecieron tres categorías de análisis, a saber: la ética profesional, la ética del contador público y la contabilidad creativa. El ejercicio de revisión documental planteado por Ander-Egg (1995), implica que:

(...) Los documentos son hechos o rastros de «algo» que ha pasado, de ahí que como "testimonios" que proporcionan información, datos o cifras, constituyan un tipo de material muy útil para la investigación social. Como elemento de 
conocimiento o fuente de información son susceptibles de ser utilizados como consulta, estudio o prueba. (p. 211)

La presente investigación se desarrolló en las siguientes fases:

i) Indagación y elección de las tres categorías de análisis.

ii) Recolección, selección y clasificación de las citas bibliográficas a través de una matriz que relaciona los siguientes criterios: tema, autor, año de la publicación, tipo de publicación, objetivo central, resumen, conclusiones, cita textual, entre otros.

iii) Análisis de las citas clasificadas según la categoría y desarrollo de la discusión, a través de la identificación de relaciones.

La revisión documental, efectuada en diversas bases de datos, arrojó el siguiente número de citas por categoría de análisis: la ética profesional, 19; la ética profesional del contador público, 8; y la contabilidad creativa, 20 citas, respectivamente.

\section{Resultados y discusión}

\subsection{La ética profesional}

Desde tiempos remotos, las civilizaciones han tratado de organizarse y dividirse en torno a la realización del trabajo en pro de ser más productivos, inicialmente en la caza y en el cultivo de los alimentos. Esto requiere de una especialización, en donde a cada persona se le encomienda una función y entre todos logran un cometido, siendo eficientes y eficaces a la vez, según la teoría de la productividad y la efectividad.

Después del trueque llega el capitalismo, con el uso de la moneda representada a través de diferentes medios como el oro y el papel, un medio de pago más rápido y menos tedioso, el cual agilizaba las operaciones entre los comerciantes (Del
Río-Cortina, Cardona-Arbeláez \& Guacarí-Villalba, 2017). Esta situación implicó la necesidad de organizar y controlar las operaciones, por medio de los registros de cuentas, en donde hombres y mujeres se especializan en el manejo de las finanzas tanto personales como empresariales. Lo anterior generó el desarrollo de la contabilidad, vista como una profesión liberal llena de desafíos en el presente siglo, caracterizado por las ideas de globalización y de competitividad empresarial. En Colombia, inicia su formalización en la década de los 90 , con la ley 43, expedida por el Congreso de la República de Colombia, CRC (1990).

La contaduría pública se puede definir, según el Consejo Técnico de la Contaduría Pública, CTCP (2009), como:

(...) una profesión que con base en conocimientos contables, jurídicos, económicos, matemáticos, administrativos, tecnológicos y humanísticos, cumple la función social de construir confianza, mediante la simplificación de la complejidad al informar sobre las actividades y aportar credibilidad a los informes sobre su objeto de trabajo, constituido por las organizaciones, entendidas estas como la manifestación de capital en su aquí y ahora. (p. 5)

En cuanto a esta profesión, es ejercida por una persona que se forma en un claustro de educación superior, que luego de cinco años, en la mayoría de los casos, recibe un título profesional que lo habilita para trabajar la contabilidad y las finanzas. El contador se considera como un actor principal y único que por medio de conocimientos y haciendo uso de sus capacidades y de sus fortalezas, debe cumplir con los objetivos de la contabilidad para satisfacer las necesidades de las empresas. Así lo establece el artículo 1 de la Ley 43 de 1990, que define al contador como:

(...) La persona natural que, mediante la inscripción que acredite su competencia 
profesional en los términos de la presente ley, está facultada para dar fe pública de hechos propios del ámbito de su profesión, dictaminar sobre estados financieros, y realizar las demás actividades relacionadas con la ciencia contable en general. (p.1)

El contador público debe tener competencias técnicas e intelectuales para llevar a cabo su profesión de manera correcta, completa y fiable. Para mantener esa competencia, deberá tener una adecuada formación profesional en una universidad acreditada, y deberá estar en constante actualización, ya que la contaduría es una carrera profesional muy cambiante en materia jurídica, tributaria y económica (Agudelo-Vargas, 2012). Además de las competencias anteriores, el profesional también debe estar formado en cuanto a ética, valores y principios que permitan ver reflejado en él un profesional virtuoso, completo y competente, siempre buscando el beneplácito social sin dejar a un lado su papel de contador público (Cañas-Vallejo, Castaño-Pérez \& Tamayo-Ramírez, 2011).

Desde lo etimológico, autores como Estrada-Beltrán (2015), definen la ética como "'carácter' o 'perteneciente al carácter'" (p. 145); para Díaz-de la Cruz y Fernández-Fernández (2016, p. 86), y Serna (2015, p. 198) significa "'costumbre' o 'hábito' [...]". Es decir, la ética se encuentra inmersa en cada ser humano desde el momento en que nace, y puede ser formada durante el crecimiento por medio del aprendizaje. Por ejemplo, los padres enseñan a sus hijos infantes a adquirir un comportamiento correcto, lo que se convierte en una costumbre, la cual hace que se facilite llevar a cabo nuevas relaciones interpersonales dentro de la sociedad, con independencia y libertad, pero supeditados a normas que rigen el comportamiento cívico y moral.

Desde la filosofía, autores como Allegro (2015) explican que "La ética tiene que ver con el comportamiento humano" (p. 71). Así mismo, Ardila-Pantoja (2014), define la ética como "(...) el estudio de lo que está bien y lo que está mal, de lo bueno y lo malo en la conducta humana" (p. 12). Para Valencia-Toro (2014): "La ética se considera como una disciplina filosófica que estudia la moral del hombre en sociedad (...) (p. 7). Igualmente, Para Pillaca-Esquivel (2002): "La ética (...) juzga lo bueno o lo malo, correcto o incorrecto, en concreto, hace un juicio de valor de la conducta humana" (pp. 75-76). Desde lo filosófico, la ética estudia el comportamiento de los seres humanos dentro de la sociedad, la manera como cada individuo se desenvuelve en ella y la forma como realiza sus quehaceres diarios. Siempre teniendo un juicio propio de sus actos, siendo consciente y llegando a la conclusión sobre si lo que hizo estuvo bien o mal, o actuó de forma libre o guiado por la costumbre, vista como un hecho moral.

Para Díaz-Castellanos, Díaz-Ramos, Díaz-Castellanos y Franco-Zanatta (2015), "La ética es la ciencia que provee las pautas para obrar honestamente, 0 sea que la ética es una ciencia normativa" (p. 137). Pero ¿Por qué la ética, hoy en día, puede llegar a ser una ciencia normativa?, en la siguiente sección se dará respuesta a este interrogante.

La ética profesional se va formando a medida que se desarrolla la profesión en el tiempo (Navia-Antezana \& Hirsch-Adler, 2015). Sobre la ética profesional, se pueden citar importantes definiciones que han hecho algunos autores:

(...) “La ética profesional significa aplicar los principios éticos a la toma de decisiones y acciones de los profesionales (...) con el fin de elevar su desempeño, prestigio y competencia". (Rojas-Mesa et al., 2004, p. 18).

“(...) la ética profesional es la ciencia normativa que estudia los deberes y los derechos de los profesionales en cuanto a tales" (García-Alvarez, 2008, p. 176). Según Fernández y Hortal, 1994, citados en Navia-Antezana \& Hirsch-Adler (2015), la ética profesional es: "[...] la indagación sistemática acerca del modo de mejorar cualitativamente y elevar 
el grado de humanización de la vida social e individual, mediante el ejercicio de la profesión" (p.102).

En vista de lo anterior, la ética profesional brinda herramientas necesarias para regular y perfeccionar la conducta del profesional en el ejercicio de su profesión. La ética profesional cimenta sus bases sobre importantes valores y principios, que determinan el rumbo, la actuación del profesional y regulan su conducta frente al ambiente laboral y social; distintos autores los han clasificado de acuerdo a sus puntos de vista, como se indica a continuación:

Para Hirsch-Adler (2004), en la ética profesional están implícitos al menos tres principios: Beneficio o beneficencia, Autonomía y Justicia. Otros principios de autores como: Pérez (1999), y Mertzman \& Madsex (1999), citados en Hirsch-Adler, 2004), son: Evitar el daño, Fidelidad, Veracidad, Confidencialidad y Honestidad.

Las Universidades hacen énfasis en sus planes de estudio en la instrucción técnico-instrumental de los estudiantes, dejando a un lado la enseñanza de fondo en lo que concierne a la ética profesional, pilar fundamental para la formación de los futuros profesionales (Espinoza-Medina, 2017).

La Universidad está obligada a formar profesionales competentes. Por ello, la ética en el proceso educativo tiene que lograr la unidad de: lo instructivo y lo educativo; de lo racional y lo afectivo; y de lo individual y lo social (Amaro-Cano, 2015, p. 718).

La ausencia de ética profesional, genera altos índices de delincuencia, inseguridad y desconfianza en el profesional (Gonzáles, 2016); la carencia de ética profesional en el contador público, produce efectos negativos que terminan afectando la reputación de la profesión y generando desconfianza en cada uno de sus miembros, lo que a su vez genera desfalcos, evasión de impuestos y la contabilidad creativa; por otro lado, García-Pasos (2017), indica que la ausencia de ética en los profesionales también se debe a la incorrecta elección de la profesión.

\subsection{La ética profesional del contador público}

La ética profesional es un compendio homogéneo de valores y principios que deben tenerse en cuenta al momento de realizar el ejercicio de la profesión contable (Vargas \& Católico-Segura, 2007). La ética profesional está directamente ligada con la calidad moral en la realización de algún encargo (Silva-Camarena, 2002). Es decir, se define como la evaluación que se hace al momento de finalizar determinada tarea y la manera en que esta fue realizada (bien o mal, voluntaria o involuntariamente). Es por esto que la actividad profesional del contador público debe contar con un soporte ético (Hirsch-Adler, 2003).

Los valores éticos y comportamientos morales se encuentran plasmados en el Código de Ética Profesional, definido por Schaps, Albanese, Briozzo y Vigier (2015), como: el conjunto estructurado de cualidades básicas, suficientes y necesarias para regular el comportamiento del contador público en el cumplimiento de los objetivos de su profesión. Estos códigos se pueden ver desde dos perspectivas:

La primera se centra en el nivel internacional (Macro): La International Federation of Accountants, IFAC, se ha encargado de emitir un Código de ética, al cual se deben ceñir todos los países afiliados a esta federación y debe servir como modelo para la elaboración del propio, con el fin de regular el comportamiento de los contadores públicos. Este código de ética se divide en tres partes, cuenta con 18 principios que regulan el ejercicio profesional, $y$ son orientados según el sector donde se trabaja (Carvajal-Sandoval, 2002).

La segunda aplica para el nivel Nacional (Micro): Dentro de la Ley 43 de 1990, en el capítulo IV, desde el título primero al sexto, se reflejan los principios, 10 en total, y las actitudes éticas que debe 
adoptar el profesional con las empresas, el Estado y sus colegas. Los entes reguladores de esta profesión en Colombia, han tratado de realizar un código de ética autóctono teniendo como base el código de ética emitido por la IFAC.

A partir de estos códigos éticos se forja el centro, la esencia, la razón de ser de la profesión de contaduría pública. Los criterios éticos indican confianza hacia los grupos de interés, permitiendo así, que la profesión y el ejercicio de: registrar, clasificar, analizar y presentar la información contable, sea fidedigno y goce de intimidad especial. Es decir, se habla de la Fe Pública, definida por Agudelo-Vargas (2012), como: "el grado de confianza que la sociedad ha depositado en una persona y como función pública es un atributo, es un patrimonio social conocido como confianza" (p. 99).

La ética va de la mano con la función de dar Fe Pública, lo cual influye en la confianza que la sociedad deposita en el contador público. Es decir, que si se actúa con transparencia y honestidad, aumentará la confianza de las personas frente a la profesión (Castaño-Ríos, Carmona-Olier, Mesa-Palacio \& Muñetón-Tamayo, 2015).

Según Hernández (2015), "El ser humano se encuentra en constante evolución, y está inmerso en un mundo globalizado, así como va evolucionando el entorno, evoluciona su forma de actuar y pensar" (p. 16). La profesión contable, en la actualidad, se ha tenido que preparar para enfrentar muchos retos, en lo que concierne al manejo de las finanzas y la exigencia de la ética en sus actuaciones de fe pública, ya que los profesionales se encuentran inmersos en un sistema donde la compra de conciencias se puede dar fácilmente por medio del dinero. En este sentido, la ética puede llegar a convertirse en una ciencia normativa ya que regula las actuaciones del profesional y lo obliga a hacer las cosas de forma correcta, tanto para el bien del contador mismo, como para proteger la reputación de la profesión, para que no se desvirtúe, evitando así cargos de conciencia y sanciones penales.

\subsection{La contabilidad creativa}

Teniendo en cuenta el ambiente tan competitivo que hoy por hoy se maneja en el ámbito laboral, en especial en la profesión contable, las presiones que una empresa ejerce sobre sus entes administrativos son muy exigentes. Estas presiones pueden desencadenar un bajo rendimiento laboral del contador público, de acuerdo a factores Psico socio económicos (Rodríguez-Urriburu, 2017). Las presiones pueden llegar a extremos como el uso de la contabilidad creativa, expresión que en los últimos años ha pasado a formar parte del lenguaje contable, influenciando negativamente la ética profesional del contador público.

La contabilidad creativa consiste en maquillar y manipular, mediante técnicas y conocimientos contables, las cifras reveladas dentro de los estados financieros de una empresa, transformando los datos mediante el aprovechamiento de lagunas normativas. Se presenta a los usuarios de la información, entre otros: los socios, accionistas, directivos, trabajadores, clientes, proveedores, competidores, comunidad, entorno, estado y sociedad en general, un informe contable utópico, y no precisamente un informe razonable (Jiménez-Aguirre, 2012). En esta práctica se encuentra una delgada línea entre la ética y la ilegalidad, lo cual la convierte en una situación éticamente reprochable (García, 2014; Ruíz-Vallejo, 2008; Calderón-Portocarrero, 2017; Bautista, 2013; Poblete-ViIlota \& Prieto-Ferias, 2005; Villalba-Pizarro, 2015).

Asimismo, Guevara \& Cosenza (2006), plantean tres causas que motivan la puesta en marcha de la contabilidad creativa: para mejorar la situación real; para presentar una situación estable y sin volatilidad en el tiempo; y para presentar una situación debilitada.

Para mejorar la situación real: he aquí un escenario propicio para todo tipo de maniobras, que conllevan a una mejora eficaz de la situación financiera de la empresa y que persigue, directamente, mostrar altos índices de liquidez y solvencia, para 
de esta manera: ganarse la confianza de los Inversionistas, acceder fácilmente a Créditos Bancarios, tener mayores Oportunidades de Negocio, entre otros (Bautista, 2013). O, como lo indica Casabianca (2005): "También es posible una mejora artificial de resultados para retribuir a los directivos con salarios ligados a beneficios" (p. 57).

Es por esto que la credibilidad de la información y la reputación de las empresas se está perdiendo frente a los inversionistas, en lo que concierne a sus estados financieros. "(...) la contabilidad creativa ha traído como consecuencia que se tenga desconfianza en la información contable de las empresas" (Sánchez-Quiñonez \& Torres-Valentierra, 2012, p. 14).

Para presentar una situación estable y sin volatilidad en el tiempo: según algunos autores, lo que conduce a esta situación es la necesidad que tiene la organización de mostrar el nivel de gestión deseado a sus integrantes e interesados, generando confianza en la misma (Calderón-Portocarrero, 2017). Todo esto con el fin de evitar excesivas fluctuaciones o volatilidad que pueda deteriorar la imagen de la empresa a largo plazo (Guevara \& Cosenza, 2006).

Para presentar una situación debilitada: en algunos casos, presentar una imagen debilitada de la situación financiera de la empresa, es la mejor opción a la hora de obtener beneficios. En este sentido, Casabianca (2005), indica que mostrar una situación financiera debilitada obedece al deseo de pagar menos impuestos.

De acuerdo a Cruz-Ramírez, Pérez-Castañeda y Piedra-Mayorga (2012): se han presentado casos alrededor del mundo, donde se ha visto afectada la información financiera de las empresas por culpa de la contabilidad creativa, generando un ambiente de dudas e incertidumbre que imposibilitan llevar a cabo una adecuada toma de decisiones. En Colombia, se han detectado escándalos financieros provenientes de la utilización de la contabilidad creativa, con el maquillaje de los estados finan- cieros. Entre los más famosos y reconocidos están: grupo DMG Noviembre 2008), por captación masiva e ilegal de dinero bajo la forma de pirámide; Los NULE (Junio 2010), carrusel de la contratación; DIAN (Julio 2011), movimientos fraudulentos de exfuncionarios para aprobar millonarias devoluciones por concepto de IVA; INTERBOLSA (Noviembre 2012), al realizar operaciones riesgosas con dinero de los inversionistas (Bautista, 2013).

Cuando un contador comete este tipo de actos, que van en contra de los objetivos de la profesión y contra todo principio ético, plasmado en el código de ética que rige la profesión, no solo afecta su imagen, sino que está afectando la imagen de todo un gremio, que se compone de más profesionales (Buitrago-Murcia, 2017). Se debe partir de que el contador público como profesional, debe dar Fe Pública; con este acto está diciendo que todos sus hechos son obrados bajo el principio de la buena $\mathrm{Fe}$, siendo consciente al mismo tiempo, que cualquier tipo de alteración mediante la falsificación de documentos, omisión de registros contables, alteración de saldos que puedan llegar a sufrir los estados financieros o la influencia de la contabilidad creativa, podrá ser denotado como delito o fraude (Velásquez, 2016).

Hoy en día, los profesionales de la contabilidad tienen un gran desafío, el cual consiste en dignificar de nuevo la profesión. Como lo afirman Splitter y Borba (2014): "se constata entonces que, para buscar crear una buena imagen frente a la sociedad, es necesaria la divulgación de las capacidades y potencialidades del profesional contable" (p.128). Villegas (2010), citado en Cari-Mamani y Burga-Montesinos (2015) afirma que: "(...) los contadores, tanto en su vida profesional como personal, deben aplicar valores y principios éticos, de esa manera evitan que su nombre e imagen se vea involucrada en faltas o asuntos ilegales" (p.27).

En lo personal, el profesional debe estar en constante actualización y formación, capacitándose en diferentes áreas del saber, complementando de esta forma sus conocimientos, convirtiéndose en 
un profesional íntegro con capacidad de toma de decisiones y asesoría en materia, financiera, jurídica y administrativa (Torres, 2015).

Varela-Moyano (2016), propone que los contadores públicos deben hacer una autoevaluación y reflexión sobre su responsabilidad social y empresarial, para de esta forma estar dispuestos a denunciar actos de fraude y corrupción que se presentan dentro de las empresas por parte de sus colegas, para acabar de una vez por todas con esta problemática que degrada la credibilidad de la profesión. En este sentido, el papel del contador público dentro de la empresa ha trascendido, ha tenido una transición desde un simple tenedor de libros, ubicado en la oficina más oscura de la empresa, a ser una persona con habilidades profesionales, formación integral y multidisciplinaria, con dotes de liderazgo y responsabilidad social mediante la fe pública (Vásconez, 2017; Panchi, 2017).

\subsection{Discusión}

Los resultados anteriores permiten establecer que existe una evidente y estrecha relación entre la ética y el desarrollo de la profesión, en este caso la contaduría pública. Estos elementos se deben articular como eslabones, ya que el no funcionamiento de uno de ellos, implica la aparición e influencia de la contabilidad creativa en el actuar del profesional. Esta última es una problemática actual en el campo contable, que cuenta con definiciones, causas y consecuencias claramente establecidas en la literatura.

La contabilidad creativa, según los autores consultados, es el maquillaje que distorsiona la información financiera de los entes económicos. Las consecuencias de su aplicación, varían de un país a otro, según su normatividad, pero el daño que genera esta práctica, siempre será considerable desde cualquier punto de vista. La contabilidad creativa se convierte en el principal problema de la profesión contable, ya que la práctica de la misma, influye en la ética profesional del contador público desencadenando problemas sociales, económicos, financieros, penales, de reputación y confianza, que afectan principalmente al gremio, a los usuarios de la información y, de manera indirecta, a la sociedad en general.

En la figura 1 se muestra que el conocimiento, la ética y la práctica del profesional contable deben permanecer unidos, teniendo como eje la ética. De esta forma se conseguirá dignificar la profesión, mediante personas aptas que desarrollen el rol de contadores públicos, cumpliendo a cabalidad con los objetivos de la contaduría pública.

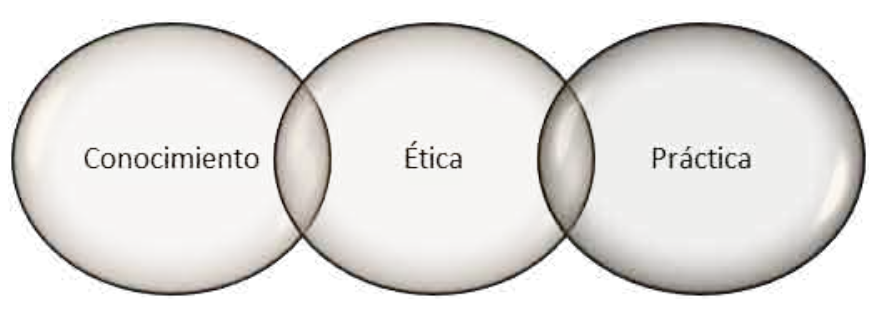

Figura 1. Dimensiones de la ética del contador público.

La contaduría pública nace ante la necesidad de perfeccionar las técnicas de recolección, registro y procesamiento de la información contable. Su objetivo es el de velar por la salud financiera de las personas naturales y jurídicas, manteniendo una estabilidad económica en la sociedad. Esto per- mite generar un ambiente ordenado, dinámico y tranquilo, donde los contadores públicos actúan bajo el principio de la fe pública.

En este sentido, para blindar a los profesionales contables del ambiente de codicia que genera el 
capitalismo mediante el dinero, se han establecido códigos de ética que deben tener en cuenta al momento de tomar sus decisiones. A nivel mundial se tiene el código de ética de la IFAC, mientras que a nivel colombiano está el código de ética plasmado en la ley 43 de 1990. Estos documentos son la columna vertebral y el punto de partida del profesional contable para mantener una buena conducta, cumpliendo con los principios y el objetivo de la contaduría pública, el cual es representar la imagen fiel de la situación financiera de las empresas.

\section{Conclusiones}

La necesidad de controlar las operaciones mercantiles entre los comerciantes, hizo que apareciera en el mundo la contabilidad y por consiguiente la figura de contador público. Este último es un sujeto encargado de: organizar, recopilar, clasificar, procesar y revelar la información contable dentro de los estados financieros, con el fin de coadyuvar en la toma de decisiones organizacionales y de análisis financiero. En este sentido, se torna importante que el profesional procese y maneje la información de forma correcta, basado en los principios de ética profesional.

La ética tiene dos acepciones respecto a su concepto, uno a nivel etimológico y otro a nivel filosófico. En el primero se deduce que la ética es inherente al ser humano desde el nacimiento y que puede ser formada a través del crecimiento de los niños por medio de sus padres, viéndose esto como una costumbre; en el segundo, la ética estudia el comportamiento y la moral del hombre dentro de la sociedad. Al contextualizar estas definiciones a nivel de la profesión contable, se dice que la ética es un pilar fundamental ya que al definirse como una ciencia normativa, regula el comportamiento del profesional durante su ejercicio contable.

La contabilidad creativa, siendo una práctica fraudulenta e ilegal consistente en maquillar las cifras contenidas en los estados financieros de las empresas, influye directamente sobre la ética profesional del contador público. Esto debido a que lo incita a actuar incorrectamente, ya sea para mejorar la situación financiera de la empresa, mostrando informes financieros utópicos, mantener una situación estable sin tanta volatilidad o simplemente para mostrar una imagen financiera desmejorada con el objetivo de pagar menos impuestos. Lo anterior obedece en ocasiones a presiones que los superiores jerárquicos de las empresas ejercen sobre los contadores, en el afán de modificar a su interés la información contable y financiera.

\section{Referencias}

Agudelo-Vargas, M. V. (2012). Reflexiones axiológicas sobre el ejercicio profesional de la contaduría pública. Revista Lúmina, 13, 88-104. Recuperado de: http://revistasum.umanizales.edu.co/ojs/index.php/Lumina/article/view/684/808

Akpanuko, E. E., \& Umoren, N. J. (2018). The influence of creative accounting on the credibility of accounting reports. Journal of Financial Reporting and Accounting, 16 (2), 292-310. https://www. researchgate.net/publication/324507533_The_influence_of_creative_accounting_on_the_credibility_of_accounting_reports

Allegro, L. (2014). Ética y educación. Inmanencia. Revista del Hospital Interzonal General de Agudos (HIGA) Eva Perón, 4 (2), 70-72. Recuperado de: http://ppct.caicyt.gov.ar/index.php/inmanencia/ article/view/6254/5634

Amaro-Cano, M. (2015). Ética social, profesional, profesoral y de la ciencia. MediSur, 13 (6), 714721. Recuperado de: http://scielo.sld.cu/pdf/ms/ v13n6/ms03613.pdf

Ander-Egg, E. (1995). Técnicas de investigación social. LUMEN, (24).

Ardila-Pantoja, M. J. (2014). Acciones del contador público en Colombia para el cumplimiento a las normas relacionadas con el comportamiento ético en el marco de las normas internacionales de información 
financiera (Trabajo de pregrado). Universidad Militar Nueva Granada, Bogotá, Colombia. Recuperado de: http://hdl.handle.net/10654/12873

Panchi, V. P. (2017). El contador en ejercicio de su profesión y el juicio profesional. Revista Órbita Pedagógica, 4 (3), 1-14. Recuperado de: http://runachayecuador.com/refcale/index.php/enrevista/ article/view/2341

Bautista, C. (2013). Una reflexión sobre la Contabilidad creativa en la empresa de hoy (Trabajo de pregrado). Universidad Militar Nueva Granada, Bogotá, Colombia. Recuperado de: http://hdl.handle. net/10654/10060

Bravo-González, S. (2011). La contabilidad creativa. AECA, 94, 34-36. Recuperado de: http://www. aeca1.org/revistaeca/revista94/94.pdf

Buitrago-Murcia, A. (2017). La responsabilidad del contador colombiano y su imparcialidad en las empresas (Trabajo de pregrado). Universidad Militar Nueva Granada, Bogotá, Colombia. Recuperado de: http://hdl.handle.net/10654/16265

Calderón-Portocarrero, R. (2017). Contabilidad creativa: la manipulación de la información mediante la aplicación de procedimientos contables incorrectos. Adversia, 1-18. Recuperado de: https://aprendeenlinea.udea.edu.co/revistas/index. php/adversia/article/view/327383

Cañas-Vallejo, S. Y., Castaño-Pérez, V., \& Tamayo-Ramírez, H. A. (2011). El contador público y su proceso de formación ética y social. Visión contable, 9, 97-106. Recuperado de: http://publicaciones. unaula.edu.co/index.php/VisionContable/article/ view/357

Cari-Mamani, R., \& Burga-Montesinos, J. J. (2015). Principios fundamentales del código de ética en las funciones del contador público dependiente del callao - sector privado (Trabajo de pregrado). Universidad Nacional del Callao, Callao, Perú. Recupe- rado de: http://repositorio.unac.edu.pe/handle/ UNAC/1524

Carvajal-Sandoval, A. R. (2002). Ley 43 de 1990 y Código de Ética de la IFAC. Apuntes Contables, (3), 59-71. Recuperado de: http://revistas.uexternado. edu.co/index.php/contad/article/view/1300/1237

Casabianca, M. L. (2005). Contabilidad creativa. Revista FCE, 3 (3), 57-63. Recuperado de: https:// dialnet.unirioja.es/descarga/articulo/5523081.pdf

Castaño-Ríos, C. E., Carmona-Olier, M. A., Mesa-Palacio, M. C., \& Muñetón-Tamayo, N. F. (2015). Prácticas profesionales contables en la empresa privada colombiana 1990-2013. Revista En-Contexto, 4 (4), 159-238. Recuperado de: http://ojs.tdea.edu.co/ index.php/encontexto/article/view/350/341

Congreso de la República de Colombia, CRC. (1990). Ley 43 de 1990: Reglamento de la profesión de Contador público. Colombia.

Consejo Técnico de la Contaduría Pública, CTCP. (2009). Orientación profesional, tarifas de honorarios profesionales. Recuperado de: https://incp.org. co/Site/2012/legislativa/honorarios.pdf

Cruz-Ramírez, D., Pérez-Castañeda, S. S., \& Piedra-Mayorga, V. M. (2012). La contabilidad creativa y su impacto en la información financiera. Revista Quipukamayoc 20 (38) 102-108. doi: http://dx.doi. org/10.15381/quipu.v20i38.4437

Del Río-Cortina, J., Cardona -Arbeláez, D., \& Guacarí-Villalba, A. (2017). Responsabilidad social empresarial y construcción de la marca: una nueva mirada a las estrategias de gestión. Revista de Investigación, Desarrollo e Innovación, 8 (1), 49-60. doi: https://doi.org/10.19053/20278306. v8.n1.2017.7370

Díaz-de la Cruz, C., \& Fernández-Fernández, J. L. (2016). Marco conceptual de la ética y la responsabilidad social empresarial: un enfoque antropoló- 
gico y estratégico. Revista Empresa y Humanismo, 19 (2), 69-118. doi: 10.15581/015.XIX.2.69-118

Díaz-Castellanos, E. E., Díaz-Ramos, C., Díaz-CasteIlanos, K., \& Franco-Zannatta, M. (2015). Ética: ¿cuál es la percepción de los jóvenes universitarios?. Revista de Estudios y Experiencias en Educación, 14 (27), 137-146. Recuperado de: https://dialnet.unirioja.es/servlet/articulo?codigo $=5287429$

Espinoza-Medina, A. M. (2017). La enseñanza de la ética como fundamento de formación pedagógica en el ejercicio profesional de la facultad de ciencias contables y financieras en las universidades de la provincia de Leoncio prado. Revista Balance's, 5 (5) 36-41. Recuperado de: http://revistas.unas.edu. pe/index.php/Balances/article/download/39/29

Estrada-Beltrán, J. (2015). Sistemas de gestión de la calidad: una herramienta imprescindible en la auditoría financiera. Revista En-Contexto, 3, 143238. Recuperado de: http://ojs.tdea.edu.co/index. php/encontexto/article/view/297/289

García, J. L. (2014). La contabilidad creativa en Nicaragua. TaxLegal, Corp. Recuperado de: http://itaxlegal.com/pdf/contabilidad_creativa_nicaragua. pdf

García-Alvarez, B. (2008). Los profesionales del Trabajo Social y la ética profesional ante los nuevos retos y necesidades sociales. Buleria, 6, 173-188. Recuperado de: http://hdl.handle.net/10612/1486

García-Pasos, C. (2017). Aportes del gobierno nacional en la degradación actual de la profesión contable en Colombia. Ágora Revista Virtual de Estudiantes, 5, 56-62. Recuperado de: http://ojs.tdea. edu.co/index.php/agora/article/view/474

Gonzáles, E. I. (2016). Valores en estudiantes de derecho. Proyección a la ética profesional: desarrollo de valores en universitarios. Revista Internacional de las Humanidades en la Educación, 5 (1), 25-39.
Recuperado de: http://journals.epistemopolis.org/ index.php/humanidades/article/view/445/55

Gonzalo-Angulo, J., \& Garvey, A.M. (2007). Ética y enseñanza de la contabilidad (una propuesta de discusión). Contaduría Universidad de Antioquia, 50, 11-42. Recuperado de: http://aprendeenlinea.udea.edu.co/revistas/index.php/cont/article/ viewFile/2120/1730

Guevara, I. R., \& Cosenza, J. P. (2004). Los auditores independientes y la contabilidad creativa: estudio empírico comparativo. Compendium, 6 (12), 5-24. Recuperado de: http://www.redalyc.org/ pdf/880/88001201.pdf

Guevara, I. R., \& Cosenza, J. P. (2006). Principales causas que motivan la Contabilidad creativa en Venezuela: la gerencia y sus herramientas de manipulación. Compendium, 16, 5-31. Recuperado de: www.redalyc.org/articulo.oa?id=88001602

Hernández, O. (2015). La auditoría interna y su alcance ético empresarial. Revista Actualidad Contable FACES, 33, 15-41. Recuperado de: http://www. redalyc.org/pdf/257/25746579003.pdf

Hernández-Gil, C., Figueroa-Ramírez, E. F., \& Correa-Corrales, L. E. (2018). Reposicionamiento de marca: el camino hacia la competitividad de las pequeñas y medianas empresas. Revista de Investigación, Desarrollo e Innovación, 9 (1), 33-46. doi: https://doi.org/10.19053/20278306.v9.n1.2018.8505

Hirsch-Adler, A. (2003). Elementos significativos de la ética profesional. Reencuentro, 38, 8-15. Recuperado de: http://www.redalyc.org/articulo. oa?id=34003802

Hirsch-Adler, A. (2004). Ética profesional como proyecto de investigación. Gredos, teoría de la educación 15, 235-258. Recuperado de: http://hdl.handle.net/10366/71944 
Jiménez-Aguirre, R. (2012). Contabilidad: entre la responsabilidad social y el interés público. Revista Criterio Libre, 10 (17), 219-234. Recuperado de: https://dialnet.unirioja.es/servlet/articulo?codigo $=4175380$

Navia-Antezana, C., \& Hirsch-Adler, A. (2015). Ética profesional en estudiantes de posgrado en dos universidades mexicanas. Revista electrónica de investigación educativa, 17 (1), 100-115. Recuperado de: http://www.scielo.org.mx/scielo.php?script=sci_arttext\&pid=S1607-40412015000100007\&In$\mathrm{g}=$ es\&tIng=es el 19 de Junio de 2018.

Poblete-Villota, C. \& Prieto-Ferias, M. (2005). Contabilidad creativa: Un maquillaje a los Estados Financieros (Tesis de pregrado). Universidad de Chile, Chile. Recuperado de: repositorio.uchile.cl/handle/2250/111494

Pillaca-Esquivel, U. (2002). La ética en el desarrollo profesional contable frente al fenómeno de la globalización. Quipukamayoc, 9 (17), 75-82. doi: http://dx.doi.org/10.15381/quipu.v9i17.5580

Rodríguez-Urriburu, F. M. (2017). Factores Psico socio económicos que inciden en los valores éticos y el rendimiento laboral del contador público en la gestión del gobierno regional de Ayacucho, 2016 (Trabajo de pregrado). Universidad católica los ángeles de Chimbote. Ayacucho, Perú. Recuperado de: http://repositorio.uladech.edu.pe/handle/123456789/2213

Rojas-Mesa, Y., Cabrales-Hernández, G., Gregorio-Chaviano, O., Santos-Jiménez, M., \& Molina-Gómez, A. M. (2004). La ética: un nuevo reto para el profesional de la información en el siglo XXI. Acimed, 12 (2), 1-1. Recuperado de: http://scielo.sld. cu/pdf/aci/v12n2/aci10204.pdf

Ruiz-Vallejo, G. J. (2008). Las normas internacionales de contabilidad y la contabilidad creativa. Cuadernos de contabilidad, 9 (24), 251-301. Recu- perado de: https://dialnet.unirioja.es/descarga/ articulo/5971961.pdf

Sánchez-Quiñones, E. V., \& Torres-Valentierra, L. V. (2012). Principios éticos contables emanados de la ley 43 de 1990 que contribuyen a combatir prácticas de contabilidad creativa en los egresados de la universidad del valle - sede pacífico periodo 20052010 (Trabajo de pregrado). Universidad del Valle, Cali, Colombia. Recuperado de: http://hdl.handle. net/10893/10703

Schlaps, K., Albanese, D., Briozzo, A., \& Vigier, H. (2015). Principio de independencia en la auditoría de pymes: Análisis comparativo de normativa nacional e Internacional y evidencia empírica para la argentina. Contabilidad y Auditoría, Investigaciones en Teoría Contable, 42, 109-140. Recuperado de: http://www.ojs.econ.uba.ar/ojs/index.php/Contyaudit/article/view/851/1485

Serna, C. A. (2015). Consideraciones sobre la globalización y la ética. Asuntos Económicos y Administrativos, 28 (01), 193-203. Recuperado de: http:// revistasum.umanizales.edu.co/ojs/index.php/ Asuntosecoyadmon/article/view/2361/2467

Silva-Camarena, J. M. (2002). ¿Qué es eso de ética profesional?. Revista Contaduría y Administración, (205), 5-11. Recuperado de: http://www.redalyc. org/pdf/395/39520502.pdf

Splitter, K., \& Borba, J. A. (2014). Percepción de Estudiantes y Profesores Universitarios sobre la Profesión del Contador: un Estudio Basado en la Teoría de los Estereotipos. REPeC, 8 (2), 126141. Recuperado de: http://www.redalyc.org/ html/4416/441642784002/

Torres-Caicedo, Y. A. (2015). Proceso contable del profesional en contaduría para una empresa de comercio exterior americana (Trabajo de pregrado). Universidad Militar Nueva Granada, Bogotá, Colombia. Recuperado de: http://hdl.handle. net/10654/6569 
Valencia-Toro, Y. (2014). Ética del contador público frente a la responsabilidad social en Colombia (Trabajo de Especialización). Universidad Militar Nueva Granada, Bogotá, Colombia. Recuperado de: http://hdl.handle.net/10654/12047

Varela-Moyano, M. L. (2016). Revisión de literatura acerca de la responsabilidad ética y social de la profesión de contaduría pública y la consecuencia de las sanciones, sobre la imagen del contador (Trabajo de pregrado). Pontificia Universidad Javeriana, Bogotá, Colombia. Recuperado de: http://hdl.handle. net/10554/19718

Vargas, C. A., \& Católico-Segura, D. F. (2007). La responsabilidad ética del Contador público. Revista activos, 7 (12), 1-13. doi: https://doi.org/10.15332/ s0124-5805.2007.0012.05
Vásconez, T. N. (2017). Cumplimiento del código de ética profesional del contador por parte de los afiliados al colegio de contadores de la provincia de Cotopaxi (Trabajo de pregrado). Universidad Técnica de Cotopaxi, Latacunga, Ecuador. Recuperado de: http://repositorio.utc.edu.ec/handle/27000/3736

Velásquez, M. A. (2016). El valor de las empresas libres de delitos financieros. Opción, 32 (13), 680703. Recuperado de: http://www.redalyc.org/ html/310/31048483033/

Villalba-Pizarro, P. A. (2015). Micro- y macro-manipulación contable. Tras los pasos del fenómeno de la contabilidad creativa (Tesis de pregrado). Universidad Pontificia Comillas, Madrid, España. Recuperado de: http://hdl.handle.net/11531/4527 
